\title{
Fairness in Resource Distribution: Relationship between Children's Moral Reasoning and Logical Reasoning
}

\author{
Derya Can - Veli Can* \\ Received: March 29, 2020; received in revised form: April 12, 2020; \\ accepted: April 15, 2020
}

\begin{abstract}
:
Introduction: The aim of this study is to examine children's moral reasoning and logical reasoning processes and the relationship between these two mechanisms. In the present study the focus is on the relationship between the factors such as fair sharing, equality, merit, ownership, opportunity in the resource allocation and logical reasoning among the children aged 5-7.

Methods: In this study, which aims to examine how the logical thinking skills differ according to the children's moral reasoning process, a survey design approach was used. Participants were 92 children aged 5 (female $\mathrm{N}=13$, male $\mathrm{N}=14$ ) and aged 6 (female $\mathrm{N}=17$, male $\mathrm{N}=18$ ), aged 7 (female $\mathrm{N}=17$, male $\mathrm{N}=13$ ). The data collected from the moral and logical reasoning tasks were analyzed in two steps. At the first step the answers of the participants were scored. At the second step their justifications were categorized. To test out hypotheses we used two general linear models to examine the age effects of Age (5-7 years) and Reasoning (equality, ownership, merit, opportunity) on children's evaluations of the vignette characters' actions. Age-related changes in children's evaluation and their logical reasoning skills related to initial distribution and transfer status were analyzed by the variance analysis.

Results: Based on the findings of the study it can be stated that the children in the age group of 6-7 evaluated negatively the reward distribution based on the outcomes due to their concerns about the inequality in the opportunities and the violation of the principle of equality. The findings of the study indicate that there is no significant difference in children's logical thinking skills depending on their age. As a result of the study, it is found that although there is no direct relationship between the moral and logical reasoning processes of children, the children who can reject the AC type inference predominantly emphasize the principle of equality. Although there is no significant relationship between moral reasoning and logical reasoning processes, it can be said
\end{abstract}

\footnotetext{
* Derya Can, Mehmet Akif Ersoy University, Faculty of Education, Burdur, Turkey; deryacakmak@mehmetakif.edu.tr

Veli Can, Burdur Anatolia İmam Hatip High School, Burdur, Turkey; okyanuscan15@gmail.com
} 


\section{Acta Educationis Generalis \\ Volume 10, 2020, Issue 3}

that children with higher levels of logical reasoning much more frequently emphasize the principle of equality in moral reasoning process.

Discussion: Research indicates that children aged around 5 consider the reward distribution based on the outcomes fair. Older children, on the other hand, evaluate the inequalities in resource distribution as unfair. These findings support the results of the study suggesting that older children consider inequal source distribution both at the first case and at the transfer cases unfair. The children's approval or disapproval of the transfer varies based on their reasoning processes. They support transfer if they emphasize the principle of equality, but they do not support it if their focus is on the principle of ownership. Older children are found to have a commitment to the principle of equality, and the difference between the 5 year age group and the 6-7-year age group is remarkable in this regard. Similar findings are reported in the previous studies, and it is generally stated that younger children are more selfish and that the tendency to distribute resources equally becomes dominant due to the increase in the age of children. Although there is no significant relationship between moral reasoning and logical reasoning processes, it can be said that children with higher levels of logical reasoning emphasize the principle of equality in moral reasoning process much more frequently.

Conclusion: Cognitivists argue that cognition and particularly reasoning have significant roles in making moral decisions. It suggests that children whose logical thinking skills are higher than others understand the necessity of equality to ensure fairness. The basic information on logic should be taught and introduced to the children from an early age. In addition, children should be ensured to use these methods through connections with both daily life and other courses at schools. It is thought that having basic logic knowledge by children will affect positively their cognitive, affective and social development. In order to examine this effect, a logic program including simple logic rules and basic inference types should be developed and the effects of such programs on the cognitive, affective and social development of children should be examined.

Key words: logical reasoning, deductive reasoning, making inferences, moral reasoning, resource allocation, fairness, equality, kindergarten, primary school.

\section{Introduction}

Piaget (1932) demonstrated that with the development of the cognitive process that reflects abstract thinking, logical thinking has improved and that provides a basis for supporting moral development. Piaget argues that as a child moves away from egocentrism, moral development begins to take place, and the child's cognitive capacity enables him to distinguish between his ego and the social environment. From the ages 6-7 the child's collaboration with his peers makes 


\section{Acta Educationis Generalis \\ Volume 10, 2020, Issue 3}

him aware of mutual respect by moving away from egocentric thoughts (Duska \& Whelan, 1977; Porubčanová \& Pasternáková, 2018). Piaget (1932) argues that children should structure their social and moral intelligence by interacting with their peers. Kohlberg (1976) stated that advanced moral reasoning depends on the logical reasoning ability. Researchers working in the field of cognitive development point out that cognition and especially reasoning play a key role in making moral decisions (Garrigan, Adlam, \& Longdon, 2018; Kohlberg, 1976; Piaget, 1932).

In reasoning studies, individuals are given some premises and results and are asked to evaluate the validity of the results. Research indicates that the vast majority of individuals prefer credible results over valid results (Newstead, Pollard, Evans, \& Allen, 1992). If a consequent is believable, people tend to accept the result without analyzing the validity of it; but if the consequent is unbelievable they try to find counter examples (Johnson-Laird, 2012) or they analyse the logical structure of the result to find an evidence to reject it (Evans, 2007). Similarly, if intuitive response about moral judgements is not satisfying or analogous to unbelievable and creates negative emotions, individuals tend to think about the situation at hand (Haidt, 2007). However, if the intuitive response is analogous to believable, individuals generally tend to accept it or to expand their justifications over their preference (Haidt, 2001). Therefore, the interaction between beliefs and logic is very important to understand the moral decision making process (Bialek \& Terbeck, 2016).

\section{Theoretical background}

\subsection{Fair resource distribution}

One of the significant contexts for the concept of fairness is resource allocation (Fehr, Bernhard, \& Rockenbach, 2008). Children spend most of their kindergarten and elementary school time by interacting and sometimes discussing issues such as toy sharing and resource allocation. Therefore, resource allocation is very important to understand children's moral development and reasoning processes (Piaget, 1932; Smetana, Jambon, \& Ball, 2014). Children understand the importance of equal distribution from early childhood. Over time, they begin to consider the merits or ownerships when determining the fairness in resource allocation (Baumard, Mascaro, \& Chevallier, 2012; Blake \& McAuliffe, 2011; Fehr et. al., 2008; Li, Spitzer, \& Olson, 2014). At around age 2 children employ the ownership rights and defend their belongings (for instance, they say "it is mine.") (Hay \& Ross, 1992; Ross, 2012). However, although they are aware of their ownership rights, they are not aware of others' rights (Rossano, Rakoczy, \&Tomasello, 2011). From age 3 they begin to be aware of others' rights, and for instance, they may want to stop a puppet trying to steal someone else's stuff (Rossano, Rakoczy, \& Tomasello, 2011). Children at around 3-4 age take the side of the object owner when ownership discussions 


\section{Acta Educationis Generalis \\ Volume 10, 2020, Issue 3}

occur. For example, when a girl who wants to prepare a card for her mother uses a boy's pen, the boy asked the girl to leave the pen. During the period between the ages 3 and 7 when the children are asked how such discussions are settled, majority of them defended the boy who was the owner of the pen (Kim \& Kalish, 2009). Children aged 4 think that their belongings can be used by others, but they cannot use the belongings of others without permission (Neary \& Friedman, 2014). At around ages 5-6 children distribute some objects such as candies or stickers based on the attempts or the outcomes of others (Noh, D'Esterre, \& Killen, 2019; Schmidt, Svetlova, Johe, \& Tomasello, 2016; Smith \& Warneken, 2016). At around ages 5-7 children do not find it appropriate for others to receive rewards based on the outcomes they produce in unequal conditions and therefore, they advocate equality (Elenbaas, 2019). Research indicates that as children age increases, they tend to correct inequalities which they observe in unfair practices (Fehr, Bernhard, \& Rockenbach, 2008; Kogut, 2012). The period of the early years of formal education is very significant for children to develop reasoning about merit, equity, equality and ownership (Conry-Murray, 2015; Noh et al., 2019; Rizzo \& Killen, 2016). In this period, children can think about ownership in sharing activities in their daily life (i.e. Nancekivell \& Fridman, 2017), and they may distribute their toys or stickers which are considered to be the rewards based on the merits (i.e. Schmidt et al., 2016). In addition, they may recognize the inequal practices in fair and unfair situations (i.e. Rizzo, Elenbaas, \& Vanderbilt, 2020). Therefore, it is important to examine how children between the ages of 5 and 7 are able to carry out moral reasoning and what they give priority to concepts such as equality, merit, and ownership.

\subsection{Logical reasoning}

Piaget argued that deductive reasoning is one of higher cognitive skills which begins to develop during the adult years. However, research findings do not completely support this hypothesis of Piaget. Because there are findings suggesting that high school students cannot manage to make reasoning using the standard logical rules (i.e. Evans, 1982). On the other hand, some findings indicate that primary and secondary school students are able to use conditional reasoning (Kodroff \& Roberge, 1975; Moshman, 2004).

Conditional reasoning is one of the most frequently analysed components of deductive reasoning. It has the form of "if $\mathrm{P}$ then Q". The second antecedent supports or rejects either the antecedent-P or the consequent-Q. It produces four inference types. One of them is called "Modus ponens" (MP) and has the form of "If P then Q. P is true." and gives the result of "Q is true." The second type is called "Modus tollens" (MT) and has the form of "If P then Q. Q is false." and gives the result of "P is false." The third type is "Affirmation of consequent" (AC). It has the form of "If P then Q. Q is true." which produces illogically valid result of " $P$ is true." The last type of inference is called "Denial of the 


\section{Acta Educationis Generalis \\ Volume 10, 2020, Issue 3}

antecedent" (DA) and has the form of "If P then Q. P is false." which gives an invalid result of "Q is false."

There is limited number of studies on conditional reasoning skills of young children (Chantel \& Markovits, 2017). Some findings suggest that these children are able to do the MP inferences or those inferences which require the form of "All P are Q. R is P. Therefore R is Q." (Dias \& Harris, 1988). However, young children experience some difficulties when they try to make MP inferences with premises that they cannot believe in reality (Dias \& Harris, 1988). It is also reported that young children tend to accept invalid results in the AC type inferences (O'Brien \& Overton, 1982). However, findings also indicate that young children reject the $\mathrm{AC}$ inferences if these inferences are given in appropriate contexts (Markovits, 2000; Markovits \& Thompson, 2008). On the other hand, logical thinking is thought to be an algorithmic and rules-based procedure (Braine \& O'Brien, 1991). This shows that young children who know some basic rules can also make deductive inferences. In addition, it seems that the ability of children to think of alternative situations not included in the premises and to produce them in the process of reasoning plays an important role in rejecting the AC type inferences (Chantel \& Markovits, 2017).

\subsection{Significance of the study}

Research suggests that factors such as working memory, abstract thinking, reasoning and attention skills play an important role in moral reasoning development (Steinbeis, 2018; Sebastian-Enesco \& Warneken, 2015). However, the number of studies about such topics is limited (Garrigan, Adlam, \& Longdon, 2018). In the present study the focus is on the relationship between the factors such as fair sharing, equality, merit, ownership, opportunity, outcome in the resource allocation and logical reasoning among the children aged 5-7. The social domain theory assumes that fairness is an essential moral element which is taken into consideration by adults and children and that children's understanding of fairness occurs in early childhood (Turiel, 2002). Recent studies suggest that various cognitive processes, including reasoning and justifications are significant components of the moral development (Nucci \& Turiel, 2009; Wainryb, Brehl, Matwin, Sokol, \& Hammond, 2005). In this context, it is thought that analyzing children's logical and moral reasoning processes and their relationship with each other will contribute to literature.

\subsection{Aim of the study}

The aim of this study is to examine children's moral reasoning and logical reasoning processes and the relationship between these two mechanisms. In the logical thinking process, based on the premises given, the skills of making correct inferences were examined and the reasons on which they based their inferences were determined. In the moral reasoning process, it is aimed to examine children's judgments and justifications in the distribution of existing 


\section{Acta Educationis Generalis \\ Volume 10, 2020, Issue 3}

resources by making use of the tasks that include equality and inequality regarding resource distribution.

Research begins with the assumption that children's logical reasoning skills will improve depending on the increase in age and that these children will emphasize the principle of equality in resource allocation more. In other words, as the age of the children increases, it is thought that their logical thinking skill and their commitment to the principle of equality will increase. In this context, the following hypotheses are developed regarding the moral and logical reasoning process:

Hypothesis 1: Children who reason based on the merit evaluate the first distribution more positively than children who emphasize opportunity or inequality.

Hypothesis 2: Children who emphasize the merit or ownership categories in their moral reasoning evaluate the transfer of resources more negatively than children who emphasize the opportunity or equality.

Hypothesis 3: Children who accept the MP inference refer to more of the main premise, while children who reject the $\mathrm{AC}$ inference refer to more of the alternative premise.

Hypothesis 4: Based on the increase in children's ages, logical thinking skills develop, and children with higher logical thinking skills put more emphasis on equality in the moral reasoning process.

Hypothesis 5: Children with higher logical thinking skills evaluate the distribution of rewards and transfer from one recipient to another more negatively in order to eliminate reward distribution based on the outcomes and the inequality of opportunity.

\section{Methods}

In this study, which aims to examine how the logical thinking skills differ according to the moral reasoning, a survey design approach was used. In studies using such survey design approach, the opinions of the participants are identified, described and the current situation is tried to be revealed (Fraenkel, Wallen, \& Hyun, 2012).

\subsection{Participants}

Participants were 92 children aged 5 (female $\mathrm{N}=13$, male $\mathrm{N}=14$ ) and aged 6 (female $\mathrm{N}=17$, male $\mathrm{N}=18$ ), aged 7 (female $\mathrm{N}=17$, male $\mathrm{N}=13$ ). They were approximately evenly divided in terms of age and gender. Therefore, the participants were from 5-7 year-old children ( $\mathrm{N}=92 ; \mathrm{MAge}=6,8, \mathrm{SD}=9$ months) enrolled in pre-kindergarten, kindergarten, or first grade at two public elementary schools in a small scale city in the south of Turkey. 


\section{Acta Educationis Generalis \\ Volume 10, 2020, Issue 3}

\subsection{Procedure}

Parental consents and children's verbal consents were obtained for all participants. The children were individually interviewed by first author in a quiet room at their schools in the spring semester of 2018-2019 school year.

\subsection{Measures}

\section{Moral reasoning task}

In order to analyze the moral reasoning skills of the participants a vignette was employed which is contained in the study by Elenbaas (2019). It covers the events in a park during the Art Day. Following the vignette the children are asked to express their views about how the resource distribution should be done taking into account the factors such as the outcomes, attempts, opportunities and inequalities in opportunities. Main characters in the vignette are those children who are primary school students having unisex names. Sample of the vignette are given as follows:

During the art day children are given a candy for every picture that they color. They are given many papers to paint. However, they should have brought their crayons from homes. It takes a whole crayon just to color one page. There are two children who brought crayons from home. Look! It is A's crayon. A has one 1 crayon. Look! These are B's crayons. B has five crayons. Both children painted the papers. As mentioned "a crayon can paint only one paper." Then, $A$ could paint one paper and B could paint five papers. The child at the park who is responsible for giving candies to the children (character $C$ ) sees that $A$ brought one crayon and painted one paper, and $B$ brought five crayons and pained five papers. $C$ takes six candies to give the characters $A$ and $B$. He gives one candy to $A$ and give five candies to $B$.

The participants were asked to evaluate the potential of having rewards (candies) taking into consideration their outcomes (painted papers) and their opportunities (the crayons the children have). This vignette was developed (Elenbaas, 2019) in order to understand that the participants are aware of the inequal opportunities in the situation occurred as a result of the fact that A brought one crayon and $\mathrm{B}$ brought five crayons. In addition, the character $\mathrm{C}$ distributed the rewards based on the outcomes of the character A and character B.

\section{Evaluation: first distribution}

The participants were asked to evaluate the act of the character $\mathrm{C}$ and to give an answer using one of the smiley/frowny face likert type scale (face 1=not okay, face $2=$ undecided, face $3=$ okay). Then, the justification for their answer was asked and children's answers were recorded.

The study goes on as follows:

The children put the candies in their bags. Another child comes to the park (the fourth character-D). The character D saw that the character A brought one crayon and painted one paper and took one candy and that the character $B$ 


\section{Acta Educationis Generalis \\ Volume 10, 2020, Issue 3}

brought five crayons and painted five papers and took five candies. The character D takes two candies from the B's bags and put them into A's bag.

\section{Evaluation: transfer}

Transfer is defined as the situation of taking a few candies from those who have more candies and giving them to the others. The children are asked whether or not the behaviour of the character D is appropriate. They are asked to indicate their response using both smiley/frowny face likert type scale (face 1= not okay, $2=$ undecided and $3=$ okay) and verbal expressions. Then, they are asked to justify their responses, and these justification statements are recorded.

\section{Logical reasoning task}

The logical reasoning skills of the participants were analyzed through five problem statements which included the MP and AC type inferences. These problem statements were developed based on the studies carried out with samples of younger children (Chantel \& Markovits, 2017; Markovits, 2000; Markovits, Venet, Janveau-Brennan, Malfait, Pion, \& Vadeboncoeur, 1996). The children are asked to evaluate the AC and MP inferences and to justify their responses. The problem statements were reviewed by a field expert and were used in a pilot study. In each problem set the participants were asked to evaluate first the AC type inference and then the MP inference. In addition, the participants were asked to justify their answers to these problem statements. Sample of the problem statements are given as follows:

1. All dogs have legs.

a. (AC) A friend of mine has an animal with legs. Is it certain that it is a dog? Why?

b. (MP) A friend of mine saw a dog. Is it certain that this dog has legs? Why?

2. All cars have wheels.

a. (AC) A friend of mine saw a vehicle with wheels. Is it certain that this vehicle is a car? Why?

b. (MP) A friend of mine saw a car. Is it certain that that car has wheels? Why?

3. All flies can fly.

a. (AC) A friend of mine saw an insect which can fly. Is it certain that this insect is a fly? Why?

b. (MP) Another friend of mine saw a fly. Is it certain that this fly can fly? Why?

4. All boots are worn on the feet.

a. (AC) A friend of mine saw a thing that is worn on the foot. Is it certain that this thing is a boot?

b. (MP) Another friend of mine saw a boot. Is it certain that this boot is worn on the foot? 


\section{Acta Educationis Generalis \\ Volume 10, 2020, Issue 3}

5. All trucks have wheels.

a. (AC) A friend of mine saw a vehicle with wheels. Is it certain that this vehicle is a truck? Why?

b. (MP) Another friend of mine saw a car. Is it certain that this truck has wheels? Why?

\subsection{Data analysis}

The data collected from the moral and logical reasoning tasks were analyzed in two steps. At the first step the answers of the participants were scored. At the second step their justifications were categorized. To test out hypotheses we used two general linear models to examine the age effects of Age (5-7 years) and Reasoning (equality, ownership, merit, opportunity) on children's evaluations of the vignette characters' actions (initial distribution and transfer, both from $1=$ "not okay" to $3=$ "okay"). Comparisons of model fit were made using the maximum likelihood estimation; restricted maximum likelihood estimation was used to interpret parameter estimates. The chi-square analysis was conducted to examine the relationship between inference and justification types. Age-related changes in children's assessment and their logical thinking skills related to initial distribution and transfer status were analyzed by the variance analysis.

\section{Moral reasoning task}

Moral reasoning task was evaluated based on the acts of both the character $\mathrm{C}$ and the character D. If the participants found their acts proper they were given 1. If they considered these acts as improper, then they were given 0 . In addition, the participants were asked to express their views about both characters using one of three faces. In addition, the participants were asked to justify their answers to these problem statements.

\section{Coding the justifications for the moral reasoning}

The coding of the participants' justifications for the moral reasoning was carried out based on the studies (Elenbaas, 2019) which is given in Table 1. The answers which provided no justification are categorized as "other." If the children have expressed opinions that are suitable for more than one category, the coding was done based on their dominant reasoning category. Coding was carried out by two raters and the inter coder coefficient is found to be Cohen's $\kappa=.89$.

Table 1

Codes about the moral reasoning process

\begin{tabular}{lll}
\hline Category & $\begin{array}{l}\text { Description } \\
\text { Equality }\end{array}$ & $\begin{array}{l}\text { Equalization of resources and } \\
\text { avoiding inequality. }\end{array}$ \\
\hline
\end{tabular}




Ownership $\begin{aligned} & \text { Emphasis on ownership and } \\ & \text { ownership rights. }\end{aligned}$
$\begin{aligned} & \text { other has five candies. It is not fair." } \\ & \text { "These candies belong to B. We } \\ & \text { cannot take them from his bags." } \\ & \text { "These candies belong to him." } \\ & \text { "He painted more paper, so he } \\ & \text { right as a requirement of output } \\ & \text { and effort. }\end{aligned}$
$\begin{aligned} & \text { Emphasis on the opportunities } \\ & \text { "A painted only one paper, so why } \\ & \text { cannot B take more candies." } \\ & \text { "It is well done. Because A did not } \\ & \text { have more crayons." } \\ & \text { context of the story. }\end{aligned}$
$\begin{aligned} & \text { "A could not paint five papers. } \\ & \text { Because he did not have five crayons. } \\ & \text { Why does not A take five candies!" }\end{aligned}$

\section{Logical reasoning task}

In problems related to the logical thinking one point is given if children give logically correct answers to both types of inference. If they respond incorrectly to either or both of the inference types, they were given zero. It is expected from children to reject the result of the AC type inferences in each set of problems and to accept the result of the MP type inference. In this case, the logical thinking score of the children may change between the scores of 0-5.

How the children participated in the study justified their results about the inferences and their acceptance and rejection were examined. In the studies the following four categories are employed in this regard: a) References to the first premise (for instance, when an antecedent like "All dogs have four legs." is given children provides such explanations as "Dogs have legs." or "Because it is a dog."), b) References to a specific or an alternative premise (for instance, "Because cats also have legs." or "all other animals have legs.") c) anecdotes (for instance, "Because I have a dog.") d) I do not know.

These four categories developed in the study by Chantel and Markovits (2017) were used in the study. However, in the study the participants were found to make references to the first antecedent, but told irrelevant statements. For instance, in the problem set which included an antecedent premise such as "All boots are worn on the feet." one of the participants provided the following irrelevant justification: "Because the boot is worn while fishing." Therefore, those answers which make a reference to the main antecedent premise, but contain an irrelevant justification are grouped in a different category.

\section{Results}

\section{Moral reasoning - initial distribution}

Table 2 indicates the views of the participants about the appropriateness of the behaviours of the character $\mathrm{C}$ and their justifications for the answers. As can be seen in Table $2,75 \%$ of the participants did not consider as proper the distribution of the rewards (candies) based on the outcomes (the number of 


\section{Acta Educationis Generalis \\ Volume 10, 2020, Issue 3}

papers painted) without having equal opportunity (crayons) $(n=69)$. Their justifications are mainly based on the assumption that equality is not provided in such a case $(83 \%) .15 \%$ of the students reported that such a reward distribution is proper $(n=23) .78 \%$ of them justified their answer using the concept of deserving this right. More specifically, they argued that B deserves more candies due to the fact that he painted more papers. This finding supports the hypothesis of the study that children who take into the merit in their evaluation will evaluate the first distribution more positively than children who take into consideration the opportunity or inequality, $\operatorname{LR} \chi^{2}(3, \mathrm{~N}=98)=74.222, \mathrm{p}<.001$. Those children who attach importance to the merit $(\mathrm{M}=2.89, \mathrm{SE}=0.32)$ are found to have much more positive views about the first distribution in contrast to the children who consider the equality $(\mathrm{M}=1.35, \mathrm{SE}=0.61)$ or the opportunity $(\mathrm{M}=1, \mathrm{SE}=0)$ much more significant in their evaluation process, $\mathrm{F}(3.91)=32.430, \mathrm{p}<.001$.

Table 2

Views of the participants about the behaviours of the character $C$

\begin{tabular}{lcccccccc}
\hline & \multicolumn{2}{c}{ Equality } & \multicolumn{2}{c}{ Merit } & \multicolumn{2}{c}{ Opportunity } & \multicolumn{2}{c}{ Others } \\
& $\underline{\mathrm{n}}$ & $\underline{\underline{0}}$ & $\underline{\underline{\mathrm{n}}}$ & $\underline{\%}$ & $\underline{\underline{\mathrm{n}}}$ & $\underline{\%}$ & $\underline{\mathrm{n}}$ & $\underline{\%}$ \\
Not okay & 57 & 82.6 & 0 & 0 & 2 & 2.9 & 10 & 14.5 \\
Okay & 0 & 0 & 18 & 78.3 & 0 & 0 & 5 & 21.7 \\
\hline
\end{tabular}

\section{Moral reasoning - transfer}

Table 3 indicates the views of the participants about the appropriateness of the behaviours of the character D and their justifications for the answers. It is found that $58 \%$ of the participants regarded the act of the character D as proper. In other words, they considered the behaviour of the character D who took some candies of the character B and gave them to the character A who was in an inequal situation, as proper. Because the character A had less crayons. However, majority of these children $(70 \%)$ thought that these candies belong to the character B based on the concept of "ownership" and therefore, the character D cannot take the candies. On the other hand, $17 \%$ of these students emphasized the concept of merit. In other words, they argued that the character B deserves all these candies due to the fact that he painted more papers, and therefore, for them the act of the character $\mathrm{D}$ is not proper. However, $42 \%$ of the students $(n=39)$ regarded the act of the character D as proper. Our hypothesis in this regard is that children who emphasize merit or ownership categories will evaluate the transfer of resources more negatively than children who emphasize the opportunity or equality. Therefore, this hypothesis is supported by the findings. In other words, the model suggesting that children will have positive views about the fact that the first distribution should be modified in order to eliminate the inequality of opportunity is found to be meaningful, LR $\chi^{2}$ (3, $\mathrm{N}=98)=88.008, \mathrm{p}<.001$. The justifications that children expressed in the process 


\section{Acta Educationis Generalis \\ Volume 10, 2020, Issue 3}

of reasoning differ significantly based on their reactions concerning the transfer, $\mathrm{F}(3,91)=33.175, \mathrm{p}<.001$. Children who reasoned based on the concept of ownership $(\mathrm{M}=1.35, \mathrm{SE}=0.88)$ evaluated this resource transfer more negatively than children who reasoned focusing on the concept of equality $(\mathrm{M}=2.72$ $\mathrm{SE}=0.599)$ and the concept of merit $(\mathrm{M}=2.11, \mathrm{SE}=0.782)$, all $\mathrm{p}<.01$. The evaluations of children who reasoned focusing on the concepts of equality, merit and opportunity did not differ significantly from each other, $\mathrm{p}>.05$.

Table 3

Views of the participants about the behaviours of the character D

\begin{tabular}{lcccccccc}
\hline & \multicolumn{2}{c}{ Equality } & \multicolumn{2}{c}{ Merit } & \multicolumn{2}{c}{ Opportunity } & \multicolumn{2}{c}{ Others } \\
& $\underline{\underline{n}}$ & $\underline{\underline{0}}$ & $\underline{\mathrm{n}}$ & $\underline{\%}$ & $\underline{\mathrm{n}}$ & $\underline{\%}$ & $\underline{\mathrm{n}}$ & $\underline{\%}$ \\
Not okay & 1 & 1.9 & 37 & 69.8 & 9 & 17 & 6 & 11.3 \\
Okay & 39 & 100 & 0 & 0 & 0 & 0 & 0 & 0 \\
\hline
\end{tabular}

\section{Logical reasoning}

Logical reasoning items contain both the MP type and the AC type inferences. If the participants answered correctly in both types they were given 1 . If their answers were incorrect, they were given 0 . Therefore, their scores might have ranged between 0 and 5 . It is found that there are only five students who accepted the result of the MP type inference, rejected the AC type inference $(5 \%)$. The mean score for the MP type inferences $(\mathrm{M}=4.8, \mathrm{SD}=0.63)$ is found to be higher than that of the $\mathrm{AC}$ type inferences $(\mathrm{M}=0.90, \mathrm{SD}=1.49)$. In short, they tend to accept both MP and AC types inferences.

It is also found that $54 \%$ of the participants' justifications make references to the first or main premises whereas $16 \%$ of them make references to the alternative (specific or general) premises (Table 4). The rate of the participants who used anecdotes to justify their answers is found to be $0.32 \%$. The rate of the participants who did not provide any justification, but said "I do not know." is found to be $11.19 \%$. The rate of the participants who referring to an anectodal stories about the main premises, but did not provide a proper justification is found to be $14.56 \%$. The answers of $4 \%$ of the students cannot be categorized. In addition to these last two categories there are some students who said "I do not know." instead of giving justification. In short, nearly $30 \%$ of the participants did not provide any justification for their answers. It is further found that $62 \%$ of the justifications for the MP type inferences and $46 \%$ of the justifications for the $\mathrm{AC}$ type inferences make references to the main premises. The rate of the references to the alternative premises in the AC type inferences is $30 \%$ while it is nearly $8 \%$ in the MP type inferences. The participants' justifications for the $\mathrm{AC}$ and MP type inferences differ in terms of the first and second categories.

As stated above the relationship between the inference types and justification types is examined through the chi-square analysis. Their justifications were 


\section{Acta Educationis Generalis \\ Volume 10, 2020, Issue 3}

analysed based on three categories. Of them the first two categories include the references to the main premise and the references to the alternative premises, respectively. The third category includes the total of the other four categories. The results of the analysis indicate that there is a significant correlation between the participants' rejection of the AC type inferences and their justifications, $\chi^{2}$ $(2, \mathrm{~N}=460)=44.565 \mathrm{p}<.001$. However, such a significant correlation is not found between their acceptance of the MP type inferences and their justifications, $\chi^{2}$ $(2, \mathrm{~N}=460)=15.471 \mathrm{p}>.05$. It is also found that the participants mostly produce the justifications for the MP type inferences making references for the first premises rather than for the AC type inferences. In regard to the AC type inferences their justifications are mostly based on the alternative premises. This result supports one of our hypothesis (H3).

Table 4

\section{Justifications of the participants}

\begin{tabular}{|c|c|c|c|c|c|c|c|c|c|c|c|c|}
\hline \multirow{3}{*}{ Inference types } & \multicolumn{12}{|c|}{ Categories for justifications } \\
\hline & \multicolumn{2}{|c|}{$\underline{1}$} & \multicolumn{2}{|c|}{$\underline{2}$} & \multicolumn{2}{|c|}{$\underline{3}$} & \multicolumn{2}{|c|}{$\underline{4}$} & \multicolumn{2}{|c|}{$\underline{5}$} & \multicolumn{2}{|c|}{$\underline{6}$} \\
\hline & $\underline{\mathrm{n}}$ & $\underline{\%}$ & $\underline{\mathrm{n}}$ & $\underline{\%}$ & $\underline{\mathrm{n}}$ & \% & $\underline{\mathrm{n}}$ & \% & $\underline{\mathrm{n}}$ & $\underline{\%}$ & $\underline{\mathrm{n}}$ & $\%$ \\
\hline AC inferences & 210 & $4 \overline{5.6}$ & 110 & 29.91 & 0 & $\overline{0}$ & 52 & $1 \overline{1.30}$ & 70 & $1 \overline{5.21}$ & 18 & $3 . \overline{9} 1$ \\
\hline MP inferences & 287 & 62.39 & 35 & 7.60 & 3 & 0.65 & 51 & 11.08 & 64 & 13.91 & 20 & 4.34 \\
\hline Total & 497 & 54 & 145 & 15.7 & 3 & 0.32 & 103 & 11.19 & 134 & 14.56 & 38 & 4.13 \\
\hline
\end{tabular}

* Justifications indicating the categories are given with their numbers as follows:

1. Those which make references to the main premise. 2 . Those which make references to the alternative premises (specific or general). 3. Those in which anecdotes are employed. 4. Those who said "I do not know." 5. Those which make references to the main premise, but do not provide any justification. 6 . Those justifications which cannot be categorized.

Table 5 presents the percentage and frequency of the justifications of the participants concerning the AC type inferences. When the AC type inference is rejected (correct answer), 9.6\% of the participants' justifications are the references to the main premises whereas $74.6 \%$ of them to the alternative premises. When the AC type inference is accepted (incorrect answer), $7.95 \%$ of the participants produced the justifications which make reference to the alternative premises. Among those students whose answer was incorrect the rate of the participants whose justifications make a reference to the main premise is $22.28 \%$. Nearly the same rate of the students produced the justifications which contain references to the first premises, but these justifications were just anecdotes $(22.01 \%)$. In other words, there is a parallelism between the rejection of the AC type inferences (respond correctly) and the justifications which made references to the alternative premises. This is an indication that those children with advanced logical reasoning can think of other alternatives instead of only thinking about the given situation. 


\section{Table 5}

Justifications of the participants for the acceptance or rejection of the AC type inferences

\section{Categories for justifications ${ }^{*}$}

\begin{tabular}{|c|c|c|c|c|c|c|c|c|c|c|c|c|c|c|}
\hline$\underline{\text { Item }}$ & $\frac{\text { Correct (1)/ }}{\text { Incorrect (0) }}$ & & 1 & & $\underline{2}$ & & 3 & & $\underline{4}$ & & $\underline{5}$ & & $\underline{6}$ & 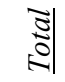 \\
\hline \multirow{3}{*}{1} & & $\underline{n}$ & $\underline{\%}$ & $\underline{n}$ & $\underline{\%}$ & $\underline{n}$ & $\underline{\%}$ & $\underline{n}$ & $\underline{\%}$ & $\underline{n}$ & $\underline{\%}$ & $\underline{n}$ & $\underline{\%}$ & $\underline{n}$ \\
\hline & 0 & 38 & 53.5 & 8 & 11.3 & 0 & 0 & $\begin{array}{l}1 \\
6\end{array}$ & 22.5 & 7 & 9.9 & 2 & 2.8 & 71 \\
\hline & 1 & 1 & 4.8 & 12 & 57.1 & 0 & 0 & 6 & 28.6 & 1 & 4.8 & 1 & 4.8 & 21 \\
\hline \multirow{2}{*}{2} & 0 & 52 & 69.3 & 2 & 2.7 & 0 & 0 & 7 & 9.3 & 11 & 14.7 & 3 & 4 & 75 \\
\hline & 1 & 5 & 29.4 & 11 & 64.7 & 0 & 0 & 1 & 5.9 & 0 & 0 & 0 & 0 & 7 \\
\hline \multirow{2}{*}{3} & 0 & 48 & 64 & 12 & 16 & 0 & 0 & 5 & 6.7 & 7 & 9.3 & 3 & 4 & 7 \\
\hline & 1 & 1 & 5.9 & 14 & 82.4 & 0 & 0 & 2 & 11.8 & 0 & 0 & 0 & 0 & 7 \\
\hline \multirow{2}{*}{4} & 0 & 26 & 34.7 & 16 & 21.3 & 0 & 0 & 7 & 9.3 & 20 & 26.7 & 6 & 8 & \\
\hline & 1 & 0 & 0 & 16 & 94 & 0 & 0 & 0 & 0 & 0 & 0 & 1 & 5.9 & 7 \\
\hline \multirow{2}{*}{5} & 0 & 38 & 46.9 & 10 & 12.3 & 0 & 0 & 8 & 9.9 & 23 & 28.4 & 2 & 2.5 & \\
\hline & 1 & 1 & 9.1 & 9 & 81.8 & 0 & 0 & 0 & 0 & 1 & 9.1 & 0 & 0 & \\
\hline
\end{tabular}

* Justifications indicating the categories are given with their numbers as follows:

1. Those which make references to the main premise. 2 . Those which make references to the alternative premises (specific or general). 3. Those in which anecdotes are employed. 4. Those who said "I do not know." 5. Those that are related to the main premise, but do not provide any justification. 6. Those justifications which cannot be categorized.

\section{Logical reasoning, moral reasoning, age}

The participants were expected to advocate the principle of equality due to the increase in their ages. It was also thought that depending increase in their age they did not find the distribution of rewards appropriate and to approve the transfer from one recipient to another to eliminate the inequal opportunity. It was examined whether there is a meaningful difference in the situation of finding the first distribution appropriate for the participants based on their age. The analysis results show that children aged 5 considered the distribution of the rewards based on the outcomes much more positively in contrast to those children aged 6 and aged $7, F(2,91)=3.425, p<.05$. It is also found that the acceptance of the children aged 6 or 7 in regard to the reward distribution based on the outcomes is less common in contrast to the children aged 5. The children's approval of the transfer does not significantly differ depending on age, $\mathrm{F}(2,91)=1.469, \mathrm{p}>.05$. However, the approval of the transfer by the children aged 6 and aged 7 (for those aged 6; $\mathrm{M}=2.23, \mathrm{SD}=0.843$; for those aged $7 ; \mathrm{M}=2.10, \mathrm{SD}=0.885$ ) is more common than that of the children aged $5(\mathrm{M}=1,85, \mathrm{SD}=0,864)$. It suggests that older children emphasize the concept of equality much more frequently. Depending on the increase in children's ages, their logical thinking skills, that is, their tendency to accept the MP type inference and to reject the AC inference, 
are expected to improve. However, no significant correlation is found between children's logical thinking skills and their age, $F(2,91)=1.040, \mathrm{p}>.05$.

This study was initiated with the assumption that children with higher-level logical thinking skills will have a higher rate of the approval of the equality principle than the other children. Therefore, the children are expected not to approve the reward distribution based on the outcomes, but to approve the transfer to eliminate the inequality in opportunities. In order to identify the children with high logical thinking skills, their tendency to produce alternative premises was examined using five problem statements which contain the AC type inferences. Because the majority of the participants accepted the MP type inferences and produced correct answers $88 \%$. However, the number of the participants who rejected the AC type inferences is very low. The children should produce the justifications based on the alternative premises in order to reject the AC type inferences. Therefore, those children who could produce three or more justifications based on the alternative premises for the AC type inferences were identified. Higher potential of the participants who produced the justifications based on the alternative premises does not significantly support the hypothesis that they would negatively evaluate the reward distribution based on the outcomes $\left(\operatorname{LR} \chi^{2}(2, \mathrm{~N}=98)=2.286, \mathrm{p}>.05\right)$ and that they would consider the source transfer positively to eliminate the inequality in opportunities, LR $\chi^{2}$ (2, $\mathrm{N}=98)=2.285, \mathrm{p}>.05$ ). There are thirteen children who produced the justifications depending on the alternative premises for the AC type inferences. However, ten of them did not approve the reward distribution based on the outcomes and they further argued that it violated the principle of equality. According to our hypothesis, those children who can produce the justifications using the alternative premises are expected to emphasize the concept of equality. Given that $76 \%$ of the children who rejected the AC type hypotheses and employed the alternative premises supported the principle of equality, the related hypothesis is supported, not significantly.

\section{Discussion}

Based on the findings of the study it can be stated that those children aged 5 much more supported the reward distribution based on the outcomes in contrast to those in the age group of 6-7. The children in the age group of 6-7 negatively evaluated the reward distribution based on the outcomes due to their concerns about the inequality in the opportunities and the violation of the principle of equality. Research also indicates that children aged around 5 consider the reward distribution based on the outcomes fair (Schmidt et al., 2016). Older children, on the other hand, evaluate the inequalities in resource distribution as unfair (Elenbaas \& Killen, 2017; Rizzo, Elenbaas, Vanderbilt, 2020). These findings support the results of the study suggesting that older children consider inequal source distribution both at the first case and at the transfer cases unfair. The children's approval or disapproval of the transfer varies based on their reasoning 


\section{Acta Educationis Generalis \\ Volume 10, 2020, Issue 3}

processes. They support transfer if they emphasize the principle of equality, but they do not support it if their focus is on the principle of ownership. Elenbaas (2019) also reported similar findings and stated that those children whose justifications are based on either ownership or merit consider transfer more negative than those whose justifications are based on the principle of equality (Elenbaas, 2019).

Conditional (if-then) reasoning is one of the significant components of higherlevel thinking processes. In the study the performance of the participants was analysed in relation to the MP and AC inference types. Although the children participated in the study tended to accept the MP type inferences and to provide correct answers, the number of children who rejected the AC type inferences and provided correct answers is found to be very low. In the study by Chantel and Markovits (2017) the rate of the students who correctly answered the MP and AC type of inferences is found to be $27 \%$ among the children aged between 41 64 months. In the current study it is found that the rate of responding correctly to both inference types is 5\% among the children aged between 50-87 months. Therefore, although older children are included in the sample of the current study, their logical reasoning scores are found to be very low. Although a large number of the participants accepted the MP type inferences and responded correctly, there are very few students who rejected the AC type inferences. As a result the total scores of the children in regard to the logical thinking questions are found to be quite low. Markovits (2000) reported that the rate of rejecting the $\mathrm{AC}$ type inferences is much more infrequent among the first grade primary school students in contrast to the second grade primary students. It is also found that it is less common among the second grade primary students in contrast to the fifth grade primary school students. These findings suggest that younger children incorrectly accept the AC inference type (Chantel \& Markovits, 2017; Markovits, 2000; O'Brien \& Overton, 1982) which support the current findings.

The main purpose of this research is to examine the relationship between children's moral and logical reasoning processes. The study started with the assumption that older children will have higher logical thinking skills and that these children will adhere to the principle of equality. However, the findings of the study indicate that there is no significant difference in children's logical thinking skills depending on their age. On the other hand, older children are found to have a commitment to the principle of equality, and the difference between the 5-year age group and the 6-7-year age group is remarkable in this regard. Similar findings are reported in the previous studies, and it is generally stated that younger children are more selfish and that the tendency to distribute resources equally becomes dominant due to the increase in the age of children (Blake \& McAuliffe, 2011; Fehr, Bernhard, \& Rockenbach, 2008; Sheskin, Bloom, \& Wynn, 2014). Although there is no significant relationship between moral reasoning and logical reasoning processes, it can be said that children with 
higher levels of logical reasoning emphasize the principle of equality in moral reasoning process much more frequently. Cognitivists argue that cognition and particularly reasoning have significant roles in making moral decisions. Piaget (1932) stated that logical reasoning develops closely related to the cognitive processes such as abstract reasoning and such a process provides a basis for moral development. Piaget (1932) argued that moral development in children occurs when they move away from egocentrism approach and reach the necessary cognitive capacity to understand the difference between the social environment and their ego. Kohlberg, on the other hand, stated that there is a parallelism between one's moral and logical stages, and stated that higher level of moral reasoning depends on higher level of logical reasoning (Kohlberg, 1984). Gibbs (2013) emphasized the effect of working memory on the development of moral reasoning and mentioned the need for attentional abilities in order to see maturation in moral reasoning process. Attentional abilities require considering the multiple dimensions of a situation and moving away from the egocentric tendency (Gibbs, 2014). In addition to emphasizing the effects of many social and affective factors in moral development, a group of researchers emphasized the importance of cognitive features such as working memory, attention, abstract reasoning and logical reasoning (Gibbs, 2014; Hoffman, 2000; Piaget, 1932). As a result of the study, it is found that although there is no direct relationship between the moral and logical reasoning processes of children, the children who can reject the AC type inference predominantly emphasize the principle of equality. It is necessary for children to be able to produce the alternative premises to reject $\mathrm{AC}$ inference. For instance, when the children are given a premise like "All dogs have legs." and a question like "I have an animal with legs. Is it certain that it is a dog?" children may give the answer of "it is not certain." if they can think about the other animals with legs. Although there were very few children who could do this, nearly $75 \%$ of them emphasized the principle of equality during the moral reasoning process. It suggests that children whose logical thinking skills are higher than others understand the necessity of equality to ensure fairness.

\section{Conclusions}

The basic information on logic should be taught and the principles of reasoning should be introduced to the children from an early age. In addition, children should be ensured to use these methods through connections with both daily life and other courses at schools. It is thought that having basic logic knowledge by children will positively affect their cognitive, affective and social development. In order to examine this effect, a logic program including simple logic rules and basic inference types should be developed and the effects of such programs on the cognitive, affective and social development of children should be examined. 


\section{References}

Baumard, N., Mascaro, O., \& Chevallier, C. (2012). Preschoolers are able to take merit into account when distributing goods. Developmental Psychology, 48, 492-498. http://doi.org/10.1037/a0026598

Białek, M., Handley, S. J., \& Terbeck, S. (2016). Moral Versus Mathematical Reflection Effects on Moral Judgments. Kozminski University Working Paper.

Blake, P. R., \& McAuliffe, K. (2011). "I had so much it didn't seem fair": Eight-year-olds reject two forms of inequity. Cognition, 120(2), 215-224. http://doi.org/10.1016/j.cognition.2011.04.006

Braine, M. D. S., \& O'Brien, D. P. (1991). A theory of if: A lexical entry, reasoning program, and pragmatic principles. Psychological Review, 98(2), 182-203. http://doi.org/10.1037/0033295X.98.2.182

Chantel, P. L., \& Markovits, H. (2017). The capacity to generate alternative ideas is more important than inhibition for logical reasoning in preschoolage children. Memory \& Cognition, 45, 208-220.

Conry-Murray, C. (2015). Boys get the math games and girls get the reading games: Children's reasoning about distributive justice and gender. Merrill-Palmer Quarterly, 61, 319-344. https://doi.org/10.13110/ merrpalmquar1982.61.3.0319

Dias, M. G., \& Harris, P. L. (1988). The effect of make-believe play on deductive reasoning. British Journal of Developmental Psychology, 6, 207221.

Duska, R., \& Whelan, M. (1977). Moral Development: A Guide to Piaget and Kohlberg. Dublin: Gill and Macmillan.

Elenbaas, L. (2019). Young children's reasoning about equality and ownership in resource conflicts. Cognitive Development, 52, 1-8.

Elenbaas, L., \& Killen, M. (2017). Children's perceptions of social resource inequality. Journal of Applied Developmental Psychology, 48, 49-58. http://dx.doi.org/10.1016/j.appdev.2016.11.006

Evans, C. S. (1982). Moral stage development and knowledge of Kohlberg's theory. Journal of Experimental Education, 51, 14-17.

Evans, J. S. B. (2007). On the resolution of conflict in dual process theories of reasoning. Think Reason, 13, 321-339.

Fehr, E., Bernhard, H., \& Rockenbach, B. (2008). Egalitarianism in young children. Nature, 454, 1079-1083.

Fraenkel, J. R., Wallen, N. E., \& Hyun, H. H. (2012). How to Design and Evaluate Research in Education. (8th ed). New York: McGraw-Hill.

Garrigan, B., Adlam, A. L. R., \& Langdon, P. E. (2018). Moral decision-making and moral development: Toward an integrative framework. Developmental Review, 49, 80-100. https://doi.org/10.1016/j.dr.2018.06.001

Gibbs, J. C. (2014). Moral Development and Reality: Beyond the Theories of Kohlberg, Hoffman, and Haidt (3rd ed.). Oxford University Press. 


\section{Acta Educationis Generalis \\ Volume 10, 2020, Issue 3}

Johnson-Laird, P. N. (2012) Inference with mental models. In K. Holyoak, \& R. Morisson (Eds.), The Oxford Handbook of Thinking and Reasoning (pp. 134-145). London: Oxford University Press.

Haidt, J. (2001). The emotional dog and its rational tail: A social intuitionist approach to moral judgment. Psychological Review, 108, 814.

Haidt, J. (2007). The new synthesis in moral psychology. Science, 316, 9981002.

Hoffman, M. (2000). Empathy and Moral Development. Implications for Justice and Caring. Cambridge, UK: Cambridge University Press. https://doi.org/10.1017/CBO9780511805851.003

Li, V., Spitzer, B., \& Olson, K. R. (2014). Preschoolers reduce inequality while favoring individuals with more. Child Development, 85(3), 1123-1133. http://doi.org/10.1111/cdev.12198

Kim, S., \& Kalish, C. W. (2009). Children's ascriptions of property rights with changes of ownership. Cognitive Development, 24(3), 322-336.

Kodroff, J. K., \& Roberge, J. J. (1975). Developmental analysis of the conditional reasoning abilities of primary-grade children. Developmental Psychology, 11, 21-28.

Kogut, T. (2012). Knowing what I should, doing what I want: From selfishness to inequity aversion in young children's sharing behavior. Journal of Economic Psychology, 33, 226-236.

Kohlberg, L. (1976). Moral stages and moralization: The cognitivedevelopmental approach. In T. Lic- kona (Ed.), Moral Development and Behavior: Theory, Research, and Social Issues. New York: Holt, Rinehart $\&$ Winston.

Markovits, H. (2000). A mental model analysis of young children's conditional reasoning with meaningful premises. Thinking \& Reasoning, 6(4), 335-347.

Markovits, H., \& Thompson, V. (2008). Different developmental patterns of simple deductive and probabilistic inferential reasoning. Memory \& Cognition, 36(6), 1066-1078. https://doi.org/10.3758/MC.36.6.1066

Markovits, H., Venet, M., Janveau-Brennan, G., Malfait, N., Pion, N., \& Vadeboncoeur, I. (1996). Reasoning in young children: Fantasy and information retrieval. Child Development, 67(6), 2857-2872. https://doi.org/10.1111/j.1467-8624.1996.tb01892.x

Moshman, D. (2004). False moral identity: Self-serving denial in the maintenance of moral selfconceptions. In D. Lapsley, \& D. Narvaez (Eds.), Morality, Self, and Identity (pp. 83-109). Mahwah, NJ: Lawrence Erlbaum Associates Inc.

Nancekivell, S. E., \& Friedman, O. (2016). "Because it's hers": When preschoolers ue ownership in their explanations. Cognitive Science, 41, 827-843. 


\section{Acta Educationis Generalis \\ Volume 10, 2020, Issue 3}

Neary, K. R., \& Friedman, O. (2014). Young children give priority to ownership when judging who should use an object. Child Development, 85, 326-337. https://doi.org/10.1111/cdev.12120.

Newstead, S. E., Pollard, P., Evans, J. S. B., \& Allen, J. L. (1992). The source of belief bias effects in syllogistic reasoning. Cognition, 45, 257-284.

Noh, J., D'Esterre, A., \& Killen, M. (2019). Effort or outcome? Children's meritorious decisions. Journal of Experimental Child Psychology, 178, 114. https://doi.org/10.1016/j.jecp.2018.09.005

Nucci, L., \& Turiel, E (2009) Capturing the complexity of moral development and education. Mind, Brain, and Education, 3(3), 151-159.

O'Brien, D. P., \& Overton, W. F. (1982). Conditional reasoning and the competence-performance issue: A developmental analysis of a training task. Journal of Experimental Child Psychology, 34(2), 274-290. https://doi.org/10.1016/0022-0965(82)90046-7

Piaget, J. (1932). The moral judgment of the child. London: Routledge Kegan Paul.

Porubčanová, D., \& Pasternáková, L (2018). Influence of socially disadvantaged environment on aggressiveness of pupils at primary schools. Acta Educationis Generalis, 8(1), 104-115. https://doi.org/10.2478/atd-20180007

Rizzo, M. T., Elenbaas, L., Cooley, S., \& Killen, M. (2016). Children's recognition of fairness and others' welfare in a resource allocation task: Age related changes. Developmental Psychology. 8, 1307-1317. https://doi.org/10.1037/dev0000134

Rizzo, M. T., Elenbaas, L., \& Vanderbilt, K. E. (2020). Do children distinguish between resource inequalities with individual versus structural origins? Child Development, 91(2), 439-455.

Rizzo, M. T., \& Killen, M. (2016). Children's understanding of equity in the context of inequality. British Journal of Developmental Psychology, 34, 569-581. http://dx.doi.org/10.1111/bjdp.12150

Rossano, F., Rakoczy, H., \& Tomasello, M. (2011). Young children's understanding of violations of property rights. Cognition, 121, 219-227. https://doi.org/10.1016/j.cognition.2011.06.007.

Schmidt, M. F. H, Svetlova, M., Johe, J., \& Tomasello, M. (2016). Children's developing understanding of legitimate reasons for allocating resources unequally. Cognitive Development, 37, 42-52. https://doi.org/10.1016/j.cogdev.2015.11.001.

Sebastián-Enesco, C., \& Warneken, F. (2015). The shadow of the future: 5-yearolds, but not 3-year-olds, adjust their sharing in anticipation of reciprocation. Journal of Experimental Child Psychology, 129, 40-54.

Sheskin, M., Bloom, P., \& Wynn, K. (2014). Anti-equality: Social comparison in young children. Cognition, 130(2), 152-156. 


\section{Acta Educationis Generalis \\ Volume 10, 2020, Issue 3}

Smetana, J. G., Jambon, M., \& Ball, C. (2014) The social domain approach to children's moral and social judgments. In M. Killen, \& J. G. Smetana (Eds.), Handbook of moral development (pp. 23-45). New York: Psychology Press.

Smith, C. E., \& Warneken, F. (2016). Children's reasoning about distributive and retributive justice across development. Development Psychology, 52(4), 613-628.

Steinbeis, N. (2018). Taxing behavioral control diminishes sharing and costly punishment in childhood. Developmental Science, 21(1), e12492.

Turiel, E. (2002). The Culture of Morality: Social Development, Context, and Conflict. Cambridge: Cambridge University Press.

Wainryb, C., Brehl, B. A., Matwin, S., Sokol, B. W., \& Hammond, S. (2005). Being hurt and hurting others: Children's narrative accounts and moral judgments of their own interpersonal conflict. Monographs of Society for Research in Child Development, 70(3), i-122. 